\title{
LA UNIVERSIDAD HOY: ¿CIENCIA Y CULTURA?
}

\author{
Jesús Salvador Moncada Cerón*
}

\section{RESUMEN}

Actualmente el saber humano se ha polarizado por medio de las especializaciones; abarcar todo el conocimiento resulta imposible en tanto que lo integran muy variadas disciplinas. Los principios de la unidad cultural, la búsqueda de la verdad en relación con el bien que hay que realizar, la relación viva de entrega y fidelidad hacia el otro derribando las barreras sociales, raciales, de género y de credo, pues todos los hombres son iguales ante Dios, son los grandes retos que afrontan las Universidades.

\section{ABSTRACT}

The modern world is characterized by the specialization of knowledge; highly trained experts dedicate their efforts to a specific discipline. Today, it is impossible for one person to master all of human learning. In this context, the great challenges facing universities are preserving cul-tural unity, the search for truth and, considering that everyone is equal before God, fostering vital interpersonal relationships based upon loyalty and dedication toward others in order to tear down social, racial, gender and religious barriers.

La universidad en sí nace profundamente humana, su objetivo era el saber y la verdad buscada a través de la investigación, la que debía de transmitir por medio de la enseñanza. Centrada en la concepción de la realidad y del saber heredado del mundo clásico de los griegos, el cual formó parte del cristianismo, el que a su vez le imbuyó su espíritu, trataba de buscar la posición del hombre dentro del mundo (cosmos) del cual formaba parte.

Para entablar diálogo con la ciencia y la cultura actual la universidad hace uso de sus elementos constitutivos a saber: la unidad del saber humano, la investigación, la docencia y la solidaridad basada en el servicio a la comunidad.

El principio fundamental característico de toda universidad es la de ser un studium generale, tal y como se afirmaba en la universidad medieval; o sea, un lugar de reflexión metodológica donde se examina a fondo la realidad con los métodos propios de cada disciplina académica, contribuyendo así al enriquecimiento del saber humano. Si bien en la época medieval el studium generale se circunscribía a un campo específico del saber humano, con el crecimiento de la universidad ésta ha llegado a transformarse en un studium universitatis, es decir, en un lugar de estudio de todas las disciplinas correspondientes al arco cultural en que se mueve la sociedad. Ciertamente el saber humano se ha polarizado, por medio de las especializaciones, que abarcar todo el conocimiento resulta imposible, pues lo integran varias disciplinas. Sin 
embargo, no conviene perder de vista el punto focal que da la ciencia, punto de convergencia de la cultura general en que vive todo hombre y tiene razón de ser por él mismo.

\section{* Estudios en Filosofía, Teología y Derecho Canónico, por la Universidad Pontificia de México. Psicología Educativa, por la Normal Superior FEP. Ciencias Religiosas y Educación, por la Universidad La Salle. jsmoncada1@yahoo.com.mx}

Hoy las universidades de los países se encuentran en una profunda crisis de identidad, por no poder identificar un principio de unidad que les haga vencer la pluridiversidad. Muchas veces las universidades son un conjunto de institutos, escuelas o facultades que funcionan por sí mismos sin tener una relación común. El studium universitatis sólo es a nivel administrativo pero nunca a nivel académico. Para que se dé esto se requiere de un fundamento común que las unifique en sus funciones de investigación y de docencia, partiendo de la base de su objeto de estudio que es la cultura humana y todo aquello que tiene relación con ella misma. Esta unidad cultural la instituyeron los antiguos como punto de arranque del estudio de la teología, la jurisprudencia y la medicina, conformando un cuadro de cultura general u orbis doctrinae (Inst. 1,10,101) como la llamaba Quintiliano. Éste se constituyó por los estudios de gramática, retórica, música, geometría y astronomía. De esta concepción surgió la noción de las artes liberales y de las artes nobles distinguiéndose así de las actividades manuales. De aquí nació el sistema del trivium y el quadrivium. El primero constaba de gramática, retórica y dialéctica, y el segundo comprendía la aritmética, geometría, astronomía y música. Este cuadro de cultura general era lo que constituía no sólo el origen académico de las facultades de las artes medievales, sino el fundamento humano que daba sentido a todo estudio de especialización en el cual consistían los studia generales o universitates. La universidad contemporánea coloca este principio en la investigación de la realidad a partir del concepto de cultura con su dimensión humanística y socio-histórica. El principio de la unidad cultural es el gran problema actual de las universidades, y muchas lo ponen en la vocación del saber, o bien en una filosofía base que sea el substrato de todas las facultades.

La unidad y transmisión del conocimiento se obtienen mediante la investigación y la docencia, dos principios pertenecientes a la universidad medieval, organizada siguiendo las formas corporativas. La universitas magistrorum se orientó fundamentalmente a la investigación producida por los maestros teniendo por objeto el saber de su disciplina, y la universitas scholarium, que tenía como finalidad el lograr aprender por medio de la docencia el conocimiento necesario para enseñar en los institutos inferiores a la universidad. Estas dos funciones que se habían venido dando en las universitates, la Universidad de Berlín, en 1810 las unió y las coloca como funciones características de la universidad moderna. El alumno no sólo debe aprender en las lecciones el conocimiento general transmitido por el profesor, sino también aprender la metodología de la investigación elaborando su propia información que 
le servirá a él mismo y pondrá al servicio de todos los demás, especialmente del cuerpo de la universidad al cual pertenece.

La universidad moderna, siguiendo su desarrollo, se adhiere a sus exigencias y une la investigación y la docencia. La universidad es una comunidad académica que de modo riguroso y crítico contribuye a la tutela y desarrollo de la dignidad humana y de la herencia cultural mediante la investigación, la enseñanza y los diversos servicios ofrecidos a las comunidades locales, nacionales e internacionales. La condición para llevar a cabo estas funciones académicas es la libertad. En la historia, la universidad cayó en crisis profunda o desapareció cuando su libertad fue abolida por la ingerencia del estado en su ordenamiento. El saber y la búsqueda de la verdad requieren un campo de libertad. De otra manera no se da la ciencia. Es prioritario garantizar la autonomía institucional de la cual debe gozar la universidad para existir y le es necesaria para cumplir sus funciones eficazmente. Hay que garantizar la libertad académica, salvaguardando siempre los derechos de la persona y de la comunidad dentro de las exigencias de la verdad y del bien común.

Otro elemento necesario de toda universidad para que sea tal, es el destino del conocimiento. En la época medieval, el destino del conocimiento logrado sobre todo por la investigación estaba identificado con la humanidad. El hombre en general era el interlocutor del studium generale. Los campos más concretos del servicio para entonces eran el de la medicina, para conceder la salud, el de la jurisprudencia de los derechos y de los bienes en la vida social, y el de la teología, el cual procuraba ofrecer el conocimiento sobre el fin trascendente del hombre.

Con la formación de las sociedades políticas modernas se comenzó a tener más conciencia de las necesidades de dichas comunidades y se empezaron a orientar los servicios de las universidades a ellas para satisfacerlas. Esto trató de hacer el estado francés; pero la pobre observación de las necesidades inmediatas les hizo perder de vista el carácter del estudio de la universidad, pues ellas fueron transformadas en institutos técnicos para obtener profesionistas útiles a la sociedad. La universidad, ciertamente, con el conocimiento de la cultura ofrece un servicio, pero este servicio va más allá de las fronteras de toda nación. Si se reflexiona sobre el Hombre, el beneficiario deberá ser el hombre y no sólo unos cuantos que integran una sociedad. Es verdad, los favorecidos inmediatos son las comunidades locales donde está enclavada la universidad, pero este conocimiento debe romper fronteras y orientarse hacia toda la humanidad. La universidad debe trabajar para el patrimonio común de la verdad y de la cultura. Actualmente la información se ha convertido en mercancía y en fuente de ganancias de los estados o de quienes patrocinan las investigaciones, lo cual en sí destruye a la universidad.

Para todos los hombres es conocido el avance de las ciencias naturales. Con la elaboración de sus propios métodos de tipo técnico a través de la observación y de la experimentación, ellas obtuvieron frutos dejando a las ciencias humanas a años luz de distancia. Aún más, ellas comenzaron a influir en la elaboración de los 
métodos de las ciencias humanas para obtener resultados positivos. Esto ha sucedido con la psicología, la sociología, la pedagogía, y la historia. Sin embargo, vemos los resultados alcanzados por las ciencias de la naturaleza. El mismo sujeto, el hombre, le tiene miedo. Lo vemos en las guerras presentes de las últimas dos décadas, donde la tecnología ha llegado a tal precisión que nos asombra. Importan más las bajas en aparatos militares y no las vidas humanas, imponiéndose la técnica sobre el hombre.

Desde luego la tecnología no debe ser reprobada, no debemos perder de vista que está al servicio del sujeto, quien la construye para su bien. Es decir, se requiere jerarquizar los valores. Los valores humanos se imponen a los valores de la tecnología manifestados en el poder, el prestigio y la riqueza. Y éste es el campo fundamental del trabajo de la universidad: promover los valores de la ciencia natural y los valores de la ciencia humana. Todos los valores son humanos, pero deberán tener más importancia los que miran directamente al hombre, y promueven el sentido de su vida en este cosmos al cual debe administrar, $y$ al valor eterno y trascendente hacia donde debe dirigirse la misma realidad del hombre.

La universidad, partiendo de la base de su objeto de estudio, la cultura humana y todo aquello con relación a ella misma, podría constituirse como una voz profética proyectada a la construcción de un ámbito verdadero para entablar un diálogo entre todos los campos de la cultura, que es producto de la sociedad en la cual se encuentra. La cultura humana deberá informar a todos los valores tecnológicos. Ella es la conciencia que de modo riguroso y crítico contribuye a la tutela y desarrollo de la dignidad humana y de la herencia cultural. Y ella debe ser el ideal de un espacio donde las diversas facultades o studium generale entren en un diálogo para llegar a una comprensión más profunda de lo que es el hombre, de su sentido en este mundo, de su función en la sociedad y de su fin trascendente.

Esto no se logra de manera espontánea, pues responde a un largo proceso histórico. Sus inicios los encontramos en la cultura griega, que heredarán los romanos. La palabra universitas es de origen latino y significa el conjunto integral y completo de los seres particulares constituidos en una colectividad determinada. Ulpiano hace referencia a la universitas de los curiales, todos los pertenecientes al cuerpo de los trabajadores de la curia forman la universitas y uno representa, ya sea de manera individual o colectiva, el nombre de la universidad, pues el derecho del cuerpo recae en uno1.

Para Marciano, la universidad no pertenece a uno, sino a todos. La compara con los teatros y los estadios de las ciudades, los cuales no pertenecen a uno, sino a todos. Quien pertenece a una universidad, o sea, a un cuerpo o conjunto de personas, debe ser evidente para todos; por ejemplo: el esclavo no es esclavo para uno, sino que es esclavo para todos 2 . 
Cicerón se refiere a la universitas rerum (totalidad de cosas que integran el universo) y la universitas generis humani (totalidad de personas, en el espacio y en el tiempo que constituyen la humanidad). El "Digesto Romano" establece la oposición entre la universitas y los singuli (D. 3, 4, 7, 1, Ulpianus $X$ ad edictum).

En la Edad Media el vocablo universitas, del cual se deriva la palabra española "universidad", se empleó originariamente para designar cualquier comunidad o corporación considerada en su aspecto colectivo. Cuando se le usaba para designar a un cuerpo dedicado a la enseñanza y a la educación se requería de un complemento, así se decía: universitas magistrorum et scholarium (totalidad del gremio maestros y alumnos).

La universitas, término que podía ser substituido por los de corpus, collegium, societas, communio, consortium, consiste en la corporación, cuya especificación podía ser de scholarium o de magistrorum, dando origen de esta manera a las dos formas típicas de tal organismo, bien como corporación de estudiantes o bien como corporación de "enseñantes".

Hacia fines del siglo XIV la palabra universitas empezó a emplearse sola, con el significado exclusivo de comunidad de maestros y de discípulos, cuya existencia corporativa había sido reconocida por autoridad eclesiástica o civil o por ambas a la vez. En nuestros días se entiende por universidad la corporación de profesores y estudiantes dedicados a los estudios superiores.

Universitas fue el nombre que se atribuyeron las agrupaciones de maestros y estudiantes pertenecientes a diversas naciones quienes concurrían al centro de enseñanza o studium ya desde el siglo XII. La designación más antigua y usual en la Edad Media era studium, y después studium generale, designación que implica un centro de instrucción para todos; es decir el generale se refería al público que podía frecuentarlo y al ámbito de los estudios que en él se realizaban.

La universidad en un primer momento fue una mera y espontánea combinación de discípulos o de maestros o de ambos cuerpos, formada probablemente a imitación de los gremios que tanta importancia adquirieron durante los siglos XIII y XIV en todos los centros comerciales y artesanales de Europa. Estas organizaciones tendían primordialmente a salvaguardar la continuación de sí mismas y a asegurar la mutua protección de sus miembros, especialmente los gremios o corporaciones de forasteros desprovistos de los derechos del ciudadano.

Es la forma medieval de las corporaciones artesanales, la que informa a la institución del studium generale, las que en sí están orientadas a la continuación de sí mismas. El ideal de la corporación de profesores (docentes) para la continuación de ella misma era el de la investigación científica realizada en una escuela, en la cual los maestros adiestraban una pequeña pero elegida cantidad de alumnos para seguir su obra; por su parte la universidad de los scholarium 
tenía como ideal lograr la licentia docendi o el título de magister o de doctor para enseñar en los institutos escolásticos de grado inferior a la universidad.

De este modo la universidad, compuesta en gran parte de estudiantes de países extranjeros, era una combinación formada para la protección de sus miembros contra las extorsiones de los ciudadanos y de otros desagradables incidentes que en tiempos medievales implicaba la residencia en un país extraño.

En su primera fase de desarrollo3 la universidad funciona por una concesión hecha por el cancelario de una catedral, o por otra autoridad análoga a determinados maestros para que abriesen otras escuelas diferentes a la catedralicia en la cercanía de las iglesias. Pero es la catedral, es decir el obispo y el cabildo de canónigos, quien amalgama a unos y a otros, da unidad a los varios studia en un studium generale, aprueba los estatutos, los programas de estudio y confiere la licentia docendi o doctorado. De esta manera fue como muchas escuelas monacales o episcopales se trasformaron en facultades donde se podían obtener los respectivos títulos.

Se dio un paso más adelante cuando las facultades consiguen este privilegio para sacudirse la férula del canónigo canciller y finalmente, para conciliar derechos y evitar riñas o dificultades, se empezó a reconocer que sin permiso del Papa, del emperador o del rey no podía constituirse un studium generale con la facultad de conferir grados académicos. Estos en un principio no significaron más que las licencias para enseñar y que, como hemos visto, eran concedidas por el cancelario escolástico u otro dignatario de una iglesia catedralicia. Después son los sumos pontífices o los reyes quienes fundan, promueven o reconocen los studia generalia, o sea, la licencia de enseñar en cualquier parte del mundo.

Se formaron entonces los gremios o corporaciones de maestros, los que otorgaban libremente sus propias licencias sin necesidad de ninguna autorización eclesiástica o civil, aunque en estos casos la licencia era de carácter local. No obstante, hacia fines del siglo XIII, algunas de las grandes escuelas, debido a la calidad de su enseñanza, tuvieron una importancia que traspasó los límites de la localidad respectiva. En realidad un doctor de Bolonia o de París podía enseñar en cualquier lugar del mundo, mientras hasta ahora empezaban a ser reconocidas las otras escuelas con el nombre de studia generalia.

Poco a poco, los studia generalia llegaron a tener un significado más técnico y definido, pues el emperador Federico II mediante una bula confiere el studium generale a la escuela de Nápoles. En el año 1229 el Papa Gregorio IX hizo lo mismo con Toulouse y en el 1233 concede el privilegio de que cualquiera que en aquella universidad se hubiera recibido de doctor o de maestro pudiera sin nuevo examen, enseñar en cualquier otra parte del mundo, dando así origen al reconocimiento retroactivo de estudios ya realizados. Subsiguientemente otras bulas papales e imperiales fundaron nuevos studia generalia y en el año 1292 la universidad de Bolonia y la de París obtuvieron las bulas de aprobación del Papa Nicolás IV. Desde entonces empezó a prevalecer entre los jurisconsultos la noción 
de que la esencia del studium generale era el privilegio de conferir el ius ubique docendi y que ningún estudio nuevo podía adquirir tal posición sin una bula papal o imperial. Sin embargo ya existían algunos estudios generales de fama notoria; así tenemos por ejemplo Oxford, a los que no se les negaba el derecho de conferir títulos aunque carecieran de dichas bulas. Estos estudios generales se consideran como studia generalia ex consuetudine. En España algunas universidades de fundación real se consideraban studia generalia respectum regni.

Para comprender de manera adecuada el desarrollo y el nuevo carácter que aquella enseñanza asumió en el curso de los siglos XII y XIII hay que ver ciertas causas que convergen para la organización de las primitivas universidades. A la aparición y desarrollo de las universidades antecedió el movimiento de renovación cultural de la época de Carlo Magno llamado renacimiento carolingio, en que apareció la primera organización de escuelas y los primeros planes de estudio; pero gran parte de esta actividad resultó ineficaz debido a la anarquía que caracterizó al mundo cristiano del siglo $X$.

No obstante las dificultades que caracterizaron los siglos llamados "obscuros", el siglo X y el XI, bajo los breñales y la maleza salvaje sobrevivió la cultura clásica y la cristiana en invernaderos: las abadías, los conventos, las bibliotecas de los cabildos catedralicios. A la sombra de las parroquias, de las catedrales y de los claustros se multiplicaron las escuelas en favor no sólo de clérigos y monjes, sino también de los pobres que no podían recurrir a preceptores particulares; esto debido al impulso de los párrocos, obispos y las disposiciones de concilios locales y en especial de los ecuménicos II y IV de Letrán (1179-1225).

Paulatinamente se va organizando en las ciudades dotadas de catedral un alumnado sediento de un saber cada vez más universal y más profundo. Surgen aquí y allá luminarias del pensamiento que se congregan en las grandes abadías para alimentar aquella sed y aprovechar las bibliotecas. Los obispos se preocupan por coordinar esta conjunción, propiciada por algunos príncipes, municipios y providenciales circunstancias. Los Sumos Pontífices alientan y armonizan los esfuerzos de unos y de otros.

En el siglo XII se organiza el esquema general de estudios a manera de propedéutica, por la que han de pasar quienes aspiran a estudios superiores; está la facultad menor de "artes", dividida en el trivium (gramática, retórica y dialéctica), y en el quadrivium (aritmética, geometría, astronomía y música). Y en el mismo siglo XII las universidades enriquecen este esquema aprovechando los conocimientos importados de origen árabe, judío y griego, con: lenguas, alquimia, matemática y medicina. La traducción latina de las obras de Aristóteles, pedida por Santo Tomás a Guillermo Moerbeke permite una estructuración más científica y racional tanto en el orden de las ciencias mismas como en la teología. Una vez cursadas las "artes" se optaba por la teología, el derecho y la medicina y posteriormente aparecieron la filosofía y otras facultades. 4 
Buen número de estudiantes eran clérigos, la mayoría de los rectores, cancilleres y maestros eran canónigos, clérigos regulares y religiosos de diversas órdenes. No había carreras cortas.

Algunas de ellas tenían duración de ocho a catorce años. Por otra parte el ansia de formación académica seria y la creciente necesidad de que hubiese personas preparadas para las curias obispales y para las aulas regias hizo que algunos centros de educación tuvieran un crecido número de estudiantes.

Para dar techo y comida a las nutridas poblaciones de alumnos, los cabildos catedralicios, las órdenes religiosas, los príncipes y algunos municipios establecieron albergues estudiantiles, los hospitia, que a su vez fueron transformándose en centros de enseñanza, en studia. A este respecto tenemos como ejemplos: el convento de los dominicos, donde por años tuvo cátedra Santo Tomás; el convento de los cordeliers o frailes menores, en donde enseñó San Buenaventura; y el colegio fundado en el año 1253 por el capellán del rey San Luis, Roberto de Sorbón, "para maestros y estudiantes pobres de teología". Tal colegio por ser la sede de las promociones de los doctores vino con el tiempo a identificarse con la facultad de teología (facultad teológica de París) y siglos después con la universidad de París, la Sorbona. Ésta posteriormente fue enriquecida y ampliada por el cardenal Richelieu.

La primera universidad que se conoce en el siglo XI es la de Salerno. Ésta había sido anteriormente una escuela de medicina, y continúa siéndolo después de que se constituye en studium generale. Federico II de Suevia, en el año 1231, la reordenó y estableció que fuese la única facultad de medicina del reino. Ésta, como la universidad de Bolonia y la de París, nacieron de una escuela especializada.

La universidad de Bolonia tiene sus raíces en el siglo XI. La facultad original fue la de leyes, a la que se añadieron alrededor del año 1200 la de medicina y la de filosofía. La facultad de teología fue reconocida hasta el año 1360 por Inocencio IV. De esta manera nacen las universitates tomadas bajo el sentido de corporación. La universidad boloñesa cultiva principalmente la ciencia del derecho civil, perfeccionado por el jurisconsulto Irnerio, y el derecho canónico, perfeccionado por Graciano, que colecciona las leyes en el Decretum Gratiani y hace de esta ciencia una disciplina autónoma. Esta universidad tiene de particular que es de estudiantes los cuales se constituyen en gremio, eligen su rector, contratan a los profesores, les pagan los sueldos y organizaban una policía especial para averiguar si los profesores llegaban a tiempo a clases y terminaban con puntualidad. Ejercía además una estricta censura sobre los libreros y copistas, con el fin de no corrompieran los textos con erratas, omisiones o interpolaciones.

En París nace la universidad de maestros quienes se agremian para afirmar poco a poco su autoridad frente a los poderes constituidos y conquista derechos estables. Posteriormente se integraron los alumnos. La unión de estos dos gremios (tanto de maestros como de estudiantes) fue lo que dio origen a la 
universidad. Tres causas convergen para la fundación y desarrollo de la universidad de París. Primeramente, la existencia de un medio escolar muy floreciente desde el siglo XII, la enseñanza dada por los victorinos y por profesores como Abelardo quien con su enseñanza atrajo hacia París un gran número de estudiantes procedentes de Italia, Inglaterra y Alemania, y por otra parte la protección de los papas y de los reyes de Francia.

El papado juega el papel principal en la organización y desarrollo de la universidad. De hecho el verdadero fundador, protector y jefe de la naciente universidad de París fue Inocencio III, a quien ésta debe, más aún que al rey, los privilegios que le concedieron la independencia. Fue también el primero que le dio los reglamentos destinados a protegerla del error. Honorio III favorece la instalación de los dominicos y franciscanos en París, y en el año 1220 recomienda a los franciscanos ante los maestros de la universidad. Gregorio IX en el año 1228 concede de manera oficial que las órdenes mendicantes formen parte del personal docente. Alejandro IV considera la universidad de París como el centro intelectual de toda la humanidad. En el año 1255 el Papa expresa:

La ciencia de las escuelas de París es en la Santa Iglesia como el árbol de la vida en el paraíso terrenal y como la lámpara resplandeciente en la casa del Señor. Como una madre fecunda en erudición hace brotar con toda abundancia de sus fuentes de doctrina salvadora, los ríos que van a regar la faz estéril de la tierra; alegra por doquiera la Ciudad de Dios y distribuye las aguas de la ciencia que hace correr por las plazas públicas para refrigerio de las almas sedientas de justicia. Es París donde el género humano, deformado por la ceguera de su ignorancia original, recobra su vista y belleza por el conocimiento de la verdadera luz que despide rayos de ciencia divina. (GILSON, 1972:371).

Tanto en París como en Bolonia los scholares forenses o forasteros agremiados constituyeron para el año 1265 un gremio de catorce naciones (franceses, picardos, provenzales, españoles, alemanes, toscanos, lombardos, romanos, etc.) al lado de los scholares cives, con estatutos propios para cada grupo. Hacia el año 1300 se congregaban allí unos diez mil estudiantes, que además del derecho civil y canónico, podían cursar otras disciplinas.

Varios elementos convergen para el nacimiento y florecimiento de la universidad. Son factores principalmente de orden político, social, cultural y religioso. Europa en el siglo XII vivía en la unidad de la cristiandad como una familia de pueblos: una sola era la fe. Las culturas y las lenguas continuaban la diversificación iniciada siglos antes pero se creía y se alababa al mismo Dios. Se dictaban las lecciones de teología, derecho, medicina y ciencias naturales en una misma lengua, el latín. Como vemos, se mantenía una unidad en la diversidad.

La reconquista parcial de España provocó la migración de eruditos árabes y judíos hacia otros países. La toma de Constantinopla en el año 1204 y el establecimiento del imperio latino de Oriente abrieron las puertas para estudiar los manuscritos conservados en Grecia y Asia menor. Estos acontecimientos permiten 
que haya un interés por el conocimiento de la lengua griega y árabe, que se multipliquen las traducciones de manuscritos de estas lenguas al latín y que se dé un enriquecimiento en las bibliotecas: la nobleza y la burguesía descubren el valor cultural que hasta entonces era poco estimado por ellas. Esto hace que promuevan los estudios, lo que les permitirá disponer de personas preparadas para poder acrecentar sus bienes y dominios. Se introducen nuevas materias de estudio, se acrecienta el material científico, se conoce mejor a Aristóteles, lo cual obliga a buscar nuevas metodologías acomodadas a cada una de las ciencias y a procurar la sistematización de cada una de ellas. Entre los años 1250 y 1270 aparecen las sumas: la de la sabiduría cristiana de San Buenaventura, la científico-filosófica de San Alberto y la teológica de Santo Tomás. Fruto de esto es el nacimiento de la escolástica.

El factor religioso es decisivo para el desenvolvimiento histórico de la universidad. Ya hemos visto cómo muchas escuelas monásticas y catedralicias desembocan en la creación del mayor número de universidades de aquel entonces. Pero además de esto en el siglo XIII nacen dos órdenes religiosas, sin las cuales no hubiese sido posible el rápido desarrollo de las universidades. En el año 1217 los dominicos entraron en París y en el 1219 llegaron los franciscanos quienes establecieron sus respectivos studia. En 1224 ambas órdenes entraron a Oxford. Por otra parte los sumos pontífices fueron los primeros en proteger las universidades al conferirles su estatuto jurídico.

En las ciencias médicas sobresalieron las universidades de Salerno, Nápoles y Montpellier, que desde fines del siglo XII se beneficiaron con las novedades científicas de los árabes, españoles y judíos. Nicolás IV otorgó a Montpellier su constitución definitiva en el año 1289.

En Inglaterra florecieron dos centros del saber. La universidad de Oxford, fue el resultado de la fusión de dos escuelas monacales del siglo XII, y se constituyó en studium generale gracias a la protección del Papa Inocencio IV. La enseñanza de Oxford tuvo una gran originalidad: el interés religioso era tan fuerte como en París, pero la manera de subordinar las ciencias a la teología era más libre. En esta universidad Aristóteles fue tan admirado como en París. Sin embargo, el centro de atención se enfocó en el elemento empírico del aristotelismo, dejando de lado al hombre metafísico. La perspectiva de la ciencia era más apegada al árabe Alhacén que al mismo Aristóteles; se da gran importancia a las ciencias naturales y a las matemáticas preparando el terreno al empirismo occamista. La universidad de Cambridge fue una prolongación de la escuela fundada por los canónigos de Saint Giles; y que posteriormente creció con las migraciones de estudiantes tanto de Oxford como de París, y con la docencia de los franciscanos y los dominicos.

A partir del año 1243 existió en Roma el studium curiae, en el que por dos períodos tuvo cátedra Santo Tomás de Aquino y que bajo Urbano IV, gran protector de la investigación científica, cobró gran auge y prestigio. La universidad de Salamanca, nació por la iniciativa de los soberanos Alfonso IX, San Fernando y 
Alfonso $\mathrm{X}$ el sabio, y en 1255 recibe del Papa Alejandro IV los privilegios y prerrogativas de studium generale.

Y así podríamos seguir enumerando la aparición de la multitud de universidades que se dieron en la Edad Media: en Francia, las universidades de Angers y Toulouse (1227- 1229) son derivaciones de la de París. Las demás, Montpellier (1137), Orléans (1235), Avignon (1303), etc., no nacen de ninguna dispersión parisiense, pero participan de los caracteres de la universidad de París. También Salamanca, Praga, Viena, Erfurt, etc.

La universidad durante su desarrollo recibirá la influencia de los nuevos estados que surgirán y del movimiento humanista. En la primera mitad del siglo XV las relaciones de los pontífices con las universidades continuaron siendo las mismas, los estados procuraron proteger y multiplicar las universidades. Pero la harán cada vez menos universitas: de una institución perteneciente a toda la humanidad y al mundo, la convierten en una institución de estado, en un centro nacional cada vez más especializado y menos rico en contenido universal y en extensión humana. Las primeras universidades en las que se solicitó la intervención exclusiva del emperador para su fundación son las de Greifswald, Friburgo y Tubinga.

Con el transcurso del tiempo la universidad llega a su declive. Lo que la viene a revitalizar es la influencia de los humanistas, sobre todo en Alemania con los trabajos de Erasmo y Reuchlin, quienes buscaban realizar un estudio crítico de las obras maestras de la antigüedad y una interpretación racional de las Escrituras y de los Padres. El principio que vino a provocar un desarrollo en la universidad entendida como studium generale fue el humanismo. Este se caracterizaba por la afirmación de la humanitas, de la crítica, de la individualidad y de la vida entendida como arte y creación. Desde luego este movimiento no apareció de la noche a la mañana, pues fue el resultado de un proceso histórico por el cual se trató de superar la contraposición abstracta de la época de la Edad Media, a la que se le consideraba dominada por la autoridad y el dogma, y por el universalismo abstracto, ético, teológico y político.

Tomando como base el concepto ciceroniano de humanitas en su significado relacionado al valor intelectual y ético del hombre, el humanismo orienta sus esfuerzos de renovación estableciendo los studia humanitatis, o de las letras humanas, que los encuentra con el contacto de la antigüedad. De ahí que en la cultura humanística se distingan dos momentos fundamentales: el uno filosófico, caracterizado por la búsqueda de aquello que sobrevivía de la civilización antigua, y el otro especulativo, caracterizado por el encuentro de una concepción humana de la vida, cuyo centro ha sido constituido por el hombre y por los valores espirituales y morales de la humanitas. Aunque estos dos momentos se distingan no pueden separarse. Ante la cultura medieval, caracterizada por su dimensión literal y dogmática, se busca al hombre que resulta de las obras de los antiguos. Y mientras se estudian tales obras se afirma el sentido de la crítica, se alargan los 
horizontes de la cultura, se universaliza el significado de la mente y se hace del hombre el centro del universo y, por tanto, objeto de atención y de estudio.

Teniendo como principio la doctrina intelectualista de Platón, Ficino construye una visión cósmica y espiritual que une en sí tanto la trascendencia como la inmanencia, y que tomó de Plotino, quien le enseñó la verdad del doble acto, según el cual ningún ser perfecto permanece inmutable consigo mismo, sino que mientras permanece en sí, emana y pasa su acción a otro, es decir a sí mismo en el otro. El universo es comparado a un cerco cuyo centro es Dios y su superficie no es más que el mismo centro en su dinamismo y desarrollo. Dios se encuentra dentro de cada ser con tal que Dios no se identifique con los entes. El hombre, por tanto, es el microcosmos que encuentra en sí las notas del macrocosmos, y es la realidad toda que se hace presente a sí misma. El centro del universo es Dios, pero el punto de vista de la reconstrucción especulativa de los grados y de las formas del ser también es el hombre. De esta manera resulta una visión antropocéntrica del mundo. Así nació el concepto de la dignidad del hombre, que es afirmada por Giovanni Pico della Mirandola y puesto como fundamento de la libertad de la mente y de la capacidad de asemejarse a cualquier cosa creada y aún a Dios mismo.

Con este movimiento filosófico-cultural del humanismo se llega al Renacimiento, en el que el ordenamiento de la universidad había madurado en su conjunto y en el que parecía agotar su vitalidad especialmente en lo que veía a la investigación. En nombre de estas nuevas ideas se llegó al desprecio de sus tradiciones y se creó un movimiento de reacción. Fue en la facultad de las artes en donde entraron los nuevos conceptos y los métodos filosóficos, como el de estudiar a Aristóteles en el texto original, de darle mayor campo a las matemáticas, astronomía, medicina, preparando así el campo a los grandes descubrimientos.

Como hemos visto el nacimiento de la universidad es predominantemente un fenómeno latino: de los primeros veinte studia generalia, dieciocho se encuentran en Francia, Italia, España y Portugal y dos en Inglaterra. En los demás países de Europa surgirán las universidades a lo largo de los siguientes siglos, y a mediados del XVI aparecerán las primeras en América: la de Santo Domingo y Lima promovidas por los dominicos, y la de México promovida por el obispo fray Juan de Zumárraga. Los antecedentes de la real y pontificia universidad de México son el colegio de San José de los Naturales y el colegio de la parroquia de la Santa Cruz de Tlatelolco, primer establecimiento de estudios superiores en América. Dan vida a la universidad dos cédulas reales en 1547, fecha oficial de su fundación y dos bulas pontificias, una de Paulo IV en 1555 y otra de Clemente VIII en 1595.

La historia de la universidad europea se puede dividir en dos épocas: la medieval y la moderna, la primera nació incluyendo como doctrina principal la teología, constituyéndose con el tiempo en su razón de ser y su fuerza vivificadora. Supo concordar la revelación con la razón, la divinidad con la humanidad, sostuvo la unidad inquebrantable de la verdad, luchó contra las 
exageraciones del nominalismo y contra el misticismo del panteísmo, preparando el terreno para las investigaciones científicas. Fue una universidad para todos, abierta a toda la humanidad dándole su fuerza de cohesión y unidad indivisa.

La noción de universidad moderna, que se apunta tras la apertura de la Universidad de Berlín en 1810, sugiere que la función de la universidad no era enseñar el conocimiento aceptado, sino demostrar cómo se habían descubierto tales conocimientos. Desde esta perspectiva, el estudio de la ciencia se consideró como el fundamento a partir del cual era viable el desarrollo de la investigación empírica. Desde finales del siglo XIX, este esquema de universidad alemana influyó decisivamente en la creación de la universidad moderna en Europa, Estados Unidos, Japón y América Latina. Fue así como el espíritu científico modernizó las estructuras tradicionales de las universidades, a la vez que propició un clima de libertades en la esfera de la enseñanza, el estudio y la investigación.

En Latinoamérica esta visión, que se ha enriquecido con los preceptos de la tradición social y humanística, ha perfilado el rumbo de las más importantes universidades de la región. No obstante, desde las últimas décadas del siglo XX los fenómenos de la globalización y de la apertura económica han ubicado a innumerables instituciones de educación superior en un papel prioritariamente utilitario, en el que la enseñanza, la investigación, el servicio a la comunidad y la unidad del saber humano están ausentes de sus propósitos, tras una lógica funcional que sólo admite intereses de orden económico.

La participación en el sector educativo regional de ciertos inversionistas nacionales y extranjeros que no tienen tradición universitaria, y cuyos fines son básicamente lucrativos, se ampara en la complacencia de un Estado que no tiene bases reguladoras muy definidas. De este modo, se desdeña el carácter social, el valor del conocimiento y el interés público que deben orientar los propósitos formativos. Al ser despojado de su cualidad de derecho individual y social, un amplio segmento de la oferta educativa se encuadra en un orden pragmático que entra en confrontación con los supuestos democráticos de la función educativa.

Ante tal panorama, urge conducir acciones que rescaten el sentido eminentemente social que ha legitimado la existencia de las universidades, en quienes se sustenta, finalmente, el desarrollo real de los pueblos.

El origen de las universitas nos brinda grandes luces sobre el papel que juega la universidad moderna. Consiste en estrechar los vínculos entre los universitarios de los diversos países, para contrarrestar los particularismos y fomentar la ayuda entre los pueblos, mediante una acción metódica al servicio de la ciencia y la cultura, pero tal tarea de la universidad que junta a los hombres y a los pueblos sería ineficaz si no culminara en una progresiva coordinación de los conocimientos entre sí. Se hace necesario buscar la comunión de los espíritus a través de la unión de la verdad. Junto con ese cuerpo de doctrina y ese ambiente de cultura característico que busca la unificación del saber, pues la universidad no es una 
simple yuxtaposición de institutos, escuelas o facultades extrañas las unas de las otras sino síntesis de todos los objetos del saber.

\section{NOTAS}

1 (D. $3,4,7,2$, Ulpianus $X$ ad edictum)

2 (D. 1, 8, 6, 1, Marcianus $\mathrm{X}$ ad edictum).

3 Para una mayor información sobre este tema se recomiendan las siguientes lecturas: RASHDALL (1985),

Universities of Europa in the Middle Aages, Londres: Oxford; LIARD,(1965), L'enseignement supérieur en France,

Paris; ZUÑIGA S,(1957), Historia de las universidades hispánicas I: medioevo, Avila; WIERUSZOUWSKI, H. (1938),

The medieval university, New York .

4 La clasificación de las ciencias en occidente se organizó en la forma griega, se añade al quadrivium la física, la psicolo gía, la metafísica, la política y la economía; cuya existencia acababa de ser revelada por los escritos de Aristóteles.

\section{REFERENCIAS}

AUTONOMÍA UNIVERSITARIA. 2004. Memorias del foro internacional. Bogotá, Asociación Colombiana de Universidades.

BEENS, F.1977. Universidades. En: Enciclopedia internacional de ciencias sociales. Tomo X. Madrid.

BRIDE, A. 1950. Universités. En: Dictionaire de théologie catholique. Tomo $\mathrm{XV}$. París.

CANO, JG. Educación y el mercado en el TLC. En: Inversión extranjera en las universidades, ¿para bien o para mal?, México, Periódico Excélsior, 19 de julio, 2006. Jus.

CASTIELLO, J. 1985. La universidad. Estudio histórico - filosófico. México,

CELAM, 1973. Los criterios en la universidad, Bogotá, Paulinas.

GILSON, E. 1972. La filosofía en la edad media. Madrid, Gredos. 
PEREIRA, J. 2002. Comunicación, cultura y globalización. Bogotá, Centro Editorial Javeriano.

RUIZ DEL CASTILLO, A. 2002. Educación superior y globalización. Bogotá, Plaza y Valdés.

SANZ, N. 2005. Legado y patrimonio de las universidades europeas. México, Centro Nacional de Evaluación para la Educación Superior, A.C. y Ediciones del Consejo de Europa.

WIERUSZOUWSKI, H. 1938. The medieval university. Nueva York

ZUÑIGA, S. (1957). Historia de las universidades hispanas, Tomo I: Medioevo. Ávila. 